\title{
What is the "real" impact of invasive plant species?
}

\author{
Jacob N Barney $^{1 *}$, Daniel R Tekiela ${ }^{1}$, Eugene SJ Dollete ${ }^{1}$, and Bradley J Tomasek ${ }^{2}$
}

Invasive plant species should be evaluated and prioritized for management according to their impacts, which include reduction in native diversity, changes to nutrient pools, and alteration of fire regimes. However, the impacts of most invasive species have not been quantified and, when measured, those impacts are based on a limited number of response metrics. As a result, invasion ecology has been overwhelmed by speculation and bias regarding the ecological consequences of invasive plants. We propose a quantitative mathematical framework that integrates any number of impact metrics as a function of groundcover and geographic extent. By making relative comparisons between invaded and uninvaded landscapes at the population scale, which results in a percent change for each metric, we overcome previous limitations that confounded the integration of metrics based on different units. Our model offers a quantitative approach to ecological impact that may allow identification of the transition from benign introduction to impactful invader, while also allowing empirical comparisons at the species and population levels that will be useful for management prioritization.

Front Ecol Environ 2013; 11(6): 322-329, doi:10.1890/120120 (published online 14 Jun 2013)

$\mathrm{A}^{\mathrm{s}}$ a consequence of globalization and the large-scale mixing of biota, invasive species are now one of the primary components of the Anthropocene (Rosenzweig 2001). The near ubiquity of introduced species across ecosystems has generated important research on their ecology, mechanisms of spread, and management. However, it is the impact these species have on ecosystems that is arguably the most important concern, yet ecologists are hamstrung by an inability to quantify and integrate them in a holistic and meaningful way (Byers et al. 2002). The economic consequences of invasive species should not be undervalued, but from a conservation and ecosystem service protection perspective, ecological consequences

\section{In a nutshell:}

- Despite the many descriptions and discussions regarding the devastating consequences of invasive plant species, few quantitative data exist that measure the ecological/environmental impacts of most invasive plants

- When impacts are measured, ecologists are limited by the inability to integrate various metrics into a single element, which precludes meaningful inter- and intraspecific comparisons

- We propose a novel quantitative mathematical framework that integrates all impact metrics as a function of groundcover and spatial extent

- Our framework permits objective comparisons of invasiveness (impactfulness), thereby fostering a better understanding of invasive plant species (and populations) and their influence on the environment

${ }^{1}$ Department of Plant Pathology, Physiology, and Weed Science, Virginia Tech, Blacksburg, VA *(jnbarney@vt.edu); ${ }^{2}$ Department of Crop Sciences, University of Illinois, Urbana, IL should be the focus of our collective attention (MA 2005).

The following quote is from a review paper of kudzu (Pueraria montana [Lour] Merr variety lobata [Willd]), discussing the impacts of this fast-growing vine on ecological function: "Lack of quantitative data and predominance of anecdotal data [are] common for many invasive species" (Forseth and Innis 2004). Kudzu is quite literally a poster child for invasive species and yet we lack even the most basic of metrics on the ecological impacts of this widespread invader. Invasive species have become so familiar and common that we think, "kudzu must be having negative impacts"; yet only a paucity of quantitative data exists on the consequences associated with most species. The same sentiment was echoed by Schmitz et al. (1997) in an earlier treatise on ecological impacts: "Most of the information on the impact of invading nonindigenous plant species... is anecdotal and observational". This lack of empiricism impedes our ability to prioritize species (or population) management and, more importantly, to identify which species are having what effects on ecosystem functions and services.

Impact - here defined as the consequence(s) of being present, which can be positive, negative, or neutral - is, according to the US Federal Government, the primary characteristic that distinguishes invasive species from non-invasive species (NISC 2005). The US Federal Government defines invasive as "not native to the region or area whose introduction (by humans) causes or is likely to cause harm to the economy or the environment, or harms animal or human health" (NISC 2005). In other words, the species in question must have a measurable (or potential) impact on something of value: economies, ecosystems, animals, or humans. There are numerous studies and examples of economic (eg DiTomaso 2000) 
and human health (eg Lanciotti et al. 1999) impacts given that the metrics are more straightforward (dollars and human lives) and the consequences are important and easily understood by the public, in addition to being much easier to quantify or estimate.

A marked difference exists between the ecological and policy communities in defining invasive species (Richardson et al. 2000; NISC 2005). In stark contrast to the federal definition above, the "ecological" definition of invasive is based on the process of invasion, particularly spread and establishment potential (Richardson et al. 2000). In this context, there is no implicit consequence of the introduced species like that in the policy definition; rather, the species must simply be capable of dispersal and establishment (Davis 2009). Paradoxically, despite this "ecological" definition, ecologists frequently cite invasive species as threatening biodiversity, ecosystem func-

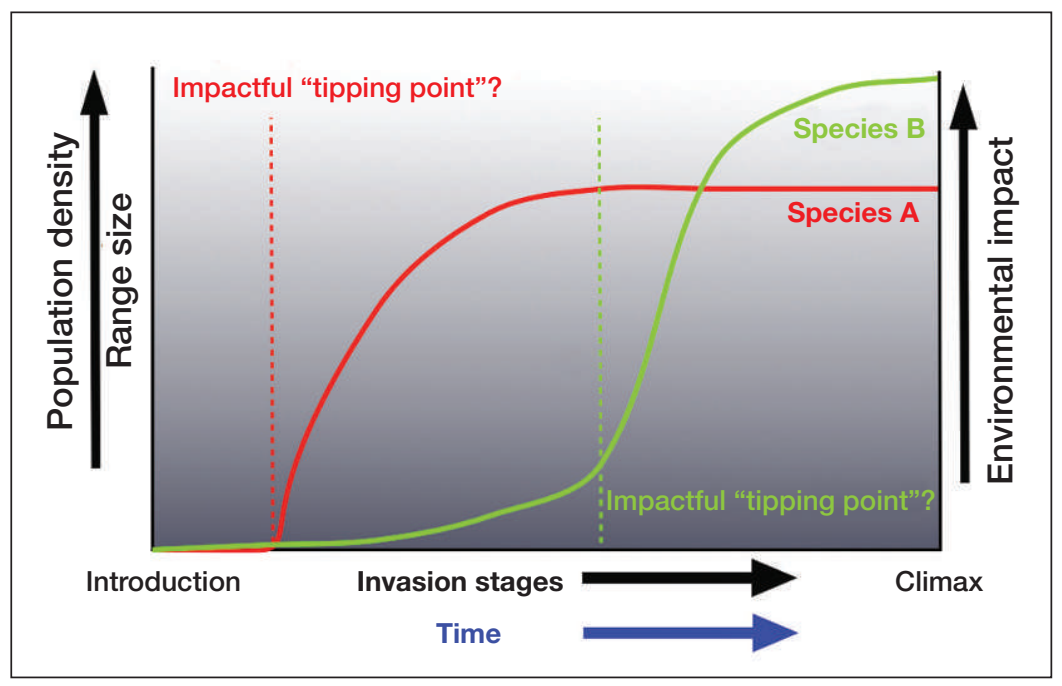

Figure 1. Hypothetical relationship between population density or range size and environmental impact of two species. The total impact and "impactful tipping point" vary between the two species. We currently have no mechanism to describe when a species has breached this tipping point and is no longer a benign component of the receiving ecosystem. tion and services, and global economies, all of which are impacts. This leads to the question: how useful is this definition of spread? In an attempt to identify whether the definition of invasive should include impact or not, Ricciardi and Cohen (2007) quantified "invasiveness" as a function of rate of establishment/spread and a categorical assignment of invader impacts to native species. The authors performed correlation analyses between these factors for plants, mammals, amphibians, reptiles, and fish and found no relationship; thus, they concluded that the definition should not connote impact (Ricciardi and Cohen 2007). As will become apparent, the authors focused only on a single impact metric and used a semi-subjective categorical assignment of impact. These limitations may seriously confound the actual impact of a species, resulting in broad but incorrect conclusions. And frankly, if there is no impact, who cares?

The argument about "impact" has taken center stage as we move beyond the need for the labels "native" and "exotic" (non-native). Davis et al. (2011) argued that the evolutionarily arbitrary designation of native or exotic distracts from the underlying importance of the consequences associated with the presence of a species. "Impacts" are overwhelmingly characterized as negative when the target species is introduced, often without the context of eventual consequence (eg increased sediment loading to a stream) or the broader ecosystem. In some cases, the impacts of native species are deemed negative (Simberloff et al. 2012), further reducing the relevance of the terms native/exotic. A global assessment of invasive plant impacts found broad evidence of change in various metrics, but noted that the direction of this change (whether positive or negative) can make interpretation difficult (Pyšek et al. 2012). Furthermore, when a change (ie impact) is measured, how do we assess its importance? All species have a measurable impact on some aspect of the receiving habitat (eg change in species richness, alteration of litter quantity/quality), which complicates the argument for a (single) impact-based framework for evaluating species (or populations).

This is not to undermine the very real consequences of some invasions. Rather, a distinction should be made between the presence of a "benign, low impact" population and a "high impact" population. However, there is currently no mechanism for identifying this "tipping point" (Figure 1). We can always measure some difference in the invaded community, even if only a single individual is represented (eg an increase in species richness), which complicates the quantification of the true impact to the receiving community. In fact, Pyšek and Hulme (2009) stated that the discipline of invasion biology will suffer until "we have a better framework for understanding the impacts of invasive species". Clearly, the discipline has struggled with terminological confusion and methodological limitations.

\section{Invasive plant impacts}

The catalog of ecological (environmental) impacts from invasive plants is long, relatively well recorded, and considered as evidence for ranking invasive species as one of the "big five" environmental issues of the 21st century (Sala et al. 2000). As described above, the impacts of interest fall into the broad categories of economics, human/animal health, and environment (we will use environmental and ecological impact interchangeably). It is the ecological impacts that are the most difficult to quantify, integrate, and rank (Table 1; Ehrenfeld 2010). Recognizing the need to parse minor effects from major 
ones, several researchers have attempted to quantify the ecological impacts of invasive species (Thiele et al. 2010 and references therein). Indeed, the first paper in the first issue of the journal Biological Invasions (Parker et al. 1999) outlined a proposed mathematical model to calculate the ecological impact of a species on a geographic scale:

$$
I=R \times A \times E \quad \text { (Equation } 1)
$$

where the impact $(I)$ is a function of the range size of the species $(R$, spatial extent of the invaded range of the entire species in square meters), average abundance per unit area across that range $(A$, number or biomass per square meter), and the per capita effect $(E)$. Despite the authors' call for a "need to be able to distinguish invaders with minor effects from those with large effects" (Parker et al. 1999), this model has not been widely adopted, with only one instance of it being used to our knowledge (giant hogweed effect on native plant richness; Thiele et al. 2010).

Although it is helpful to organize and (potentially) rank species, all of the existing impact frameworks suffer from common drawbacks (see Table 2 for a list of assorted frameworks). First, several of the frameworks are qualitative and require categorization of various impact metrics into groups (eg "weak", "moderate", "strong"; Olenin et al. 2007). This has the obvious disadvantage of not being quantitative, thereby introducing subjectivity based on the user's biases and interpretations of available information, which can often be quite limited. Second, several of the frameworks are designed to quantify impact on a per capita basis (eg Parker et al. 1999), which simplifies extrapolation to any population size, yet precludes the ability to compare impact values among species that vary

Table 1. Different levels, types, and metrics of invasive plant impacts (Thiele et al. 2010; Vilà et al. 2011)

\begin{tabular}{|c|c|c|}
\hline Level & Impact type & Impact metric \\
\hline \multirow[t]{2}{*}{ Individual } & Fitness & $\begin{array}{l}\text { Seed number, seed viability, survival, } \\
\text { germination rate, recruitment }\end{array}$ \\
\hline & Growth & Plant size, root:shoot ratio \\
\hline \multirow[t]{4}{*}{ Community } & Productivity & Biomass, net primary productivity \\
\hline & Diversity & Richness, evenness, alpha diversity, seed bank \\
\hline & Abundance & Number of individuals, density \\
\hline & Intraspecific & Genetic diversity, intrinsic growth rate $(\lambda)$ \\
\hline Structure & Physiognomy & Tree, shrub, forb, grass coverage \\
\hline \multirow[t]{4}{*}{ Biogeochemical } & Pools & $\mathrm{N}, \mathrm{C}$, phosphorus, soil organic matter \\
\hline & Litter & Litter nutrient content, $\mathrm{C}: \mathrm{N}$, decomposition rate \\
\hline & Fluxes & $\mathrm{N}, \mathrm{C}$ turnover, $\mathrm{pH}$, salinity \\
\hline & Moisture & Plant-available water \\
\hline \multirow[t]{5}{*}{ Ecosystem } & Food chain & Trophic connections, trophic-level ratio \\
\hline & Interactions & Mutualists, herbivore, parasite, pollinator diversity \\
\hline & Fluxes & Nutrient, sediment \\
\hline & Disturbance & Fire, flood frequency/intensity \\
\hline & Geomorphology & Hydrology, sediment gain/loss \\
\hline
\end{tabular}

in size. Is it meaningful to compare the large perennial grass Arundo donax to the small annual grass Microstegium vimineum on a per capita basis? Finally, and most importantly, the quantitative frameworks (Parker et al. 1999; Ricciardi 2003) are relegated to a single impact metric (eg native species richness, nitrogen $[\mathrm{N}]$ pool, litter decomposition). Single impact metric systems may be appropriate when specific ecosystem functions are more highly valued than others (eg water quality). Yet this overlooks the larger context of the consequences of invaders, which in reality is a combination of impacts with small, large, and neutral effects. In fact, Hulme et al. (2013) pointed out that most impact studies record only a few metrics, further evidence that ecologists are unable to assess the broader context of the effect of invasive species on ecosystem structure and function.

The various single-metric quantitative and multi-metric qualitative frameworks have their advantages and disadvantages, but none are capable of integrating several (let alone all) metrics of interest into a single quantitative framework. At first glance this may seem to be a trivial limitation, but we believe that invasion ecology will languish in the realm of subjectivity and bias in the absence of such a framework.

\section{The "impact cliff" - a novel integrative framework}

Our search for an integrative quantitative framework was driven by several factors: (1) the gaps in existing data and methods to quantify impact; (2) an attempt to create a framework to distinguish benign populations/species from invasive populations/species and "identify" thresholds in the relationship between extent of invasion and impacts (Figure 1); (3) the proposal of a new method of functionally integrating metrics, designed to allow (4) inter- and intraspecific comparisons in a meaningful way and to serve as (5) a valuable tool for invasion ecology and management because it allows comparisons among impacts of populations/species, and can be used to identify thresholds. This presents several challenges, given that the number of potential impact metrics of interest is large (Table 1) and the units are extremely variable (eg richness $=$ number of species, carbon $[\mathrm{C}]$ pool $=$ mass per unit volume). As Parker et al. (1999) pointed out, the way "to combine such lists of metrics into a single number representing impact is not at all obvious".

Although they did not address this challenge, Parker et al. (1999) suggested that impact should be assessed at the individual level (ie per capita), which would then be multiplied by density and range size to get a single impact 
value. As noted above, this imposes limitations when attempting to make interspecific comparisons with large size discrepancies. Furthermore, in situ quantification on a per capita basis would require averaging a metric at a given density, because measuring at the individual level is impractical. Therefore, depending on the density in which the measurement was taken, the per capita effect ( $E$ in Equation 1 ) could vary dramatically. For example, if an $E$ of 10 was recorded at 10 individuals per square meter (ie total impact of 100 divided by 10 individuals in $1 \mathrm{~m}^{2}$ ), it is unlikely that the same per capita effect would occur if those same 10 individuals occurred over $100 \mathrm{~m}^{2}$. There certainly exists a density-dependent effect, which is overlooked when considering per capita effects (eg Angeloni et al. 2006). Additionally, a survey of the existing impact studies reveals that density or percentage groundcover

\section{Table 2. Existing frameworks and functions that address invasive species impacts}

\begin{tabular}{|c|c|c|c|c|c|c|}
\hline Function & Purpose & Response variable & $\begin{array}{l}\text { Impact on } \\
\text { biodiversity/ } \\
\text { ecosystem } \\
\text { function? }\end{array}$ & $\begin{array}{l}\text { Includes } \\
\text { multiple } \\
\text { impacts? }\end{array}$ & Notes & Reference \\
\hline$I=R \times A \times E$ & $\begin{array}{l}\text { Quantification of } \\
\text { ecological impacts }\end{array}$ & $\begin{array}{l}I=\text { overall impact } \\
\text { on single metric }\end{array}$ & Yes & No & $\begin{array}{l}\text { Relates per capita } \\
\text { impact }(E) \text { to range } \\
\text { size }(R) \text { and average } \\
\text { abundance }(A) \text {; meant } \\
\text { for use at the geogra- } \\
\text { phic scale for species }\end{array}$ & $\begin{array}{l}\text { Parker et al. } \\
\text { (I999) }\end{array}$ \\
\hline$I=F_{t} \times F_{\mathrm{e}} \times F_{s} \times E$ & $\begin{array}{l}\text { Stage-based } \\
\text { ecological impacts }\end{array}$ & $I=$ per capita impact & Yes & No & $\begin{array}{l}\text { Adds invasion stages } \\
\text { to Parker et al. (1999) } \\
\text { model }\end{array}$ & $\begin{array}{l}\text { Lockwood } \\
\text { et al. (2007) }\end{array}$ \\
\hline Impact $=A \times F \times C$ & Functional impact & $\begin{array}{l}\text { Impact }=\text { measurable } \\
\text { changes to the } \\
\text { properties of an } \\
\text { ecosystem }\end{array}$ & Yes & No & $\begin{array}{l}F=\text { ecological } \\
\text { function (per capita } \\
\text { effect); } \\
C=\text { composition of } \\
\text { the recipient } \\
\text { community }\end{array}$ & $\begin{array}{l}\text { Ricciardi } \\
(2003)\end{array}$ \\
\hline$I=\sum_{j=1}^{m}\left(R_{j} \times \frac{\sum_{i=1}^{n_{j}}\left(A_{j i} \times E_{j i}\right)}{n_{j}}\right)$ & $\begin{array}{l}\text { Habitat-sensitive } \\
\text { impact }\end{array}$ & $\begin{array}{l}I=\text { overall impact } \\
\text { on single metric }\end{array}$ & Yes & No & $\begin{array}{l}\text { Per capita impact is } \\
\text { not linearly related } \\
\text { over the range of } \\
\text { abundances }\end{array}$ & $\begin{array}{l}\text { Thiele et al. } \\
(2010)\end{array}$ \\
\hline $\begin{array}{l}\text { (Refer to equation at } \\
\text { bottom of table) }\end{array}$ & $\begin{array}{l}\text { Index of Alien } \\
\text { Impact (IAI) } \\
\text { estimates } \\
\text { collective } \\
\text { ecological impact }\end{array}$ & $\begin{array}{l}\text { IAI summarizes } \\
\text { frequency of } \\
\text { occurrence and } \\
\text { potential ecological } \\
\text { impact }\end{array}$ & No & Yes & $\begin{array}{l}\text { Includes ecological } \\
\text { species traits into an } \\
\text { Invasiveness-Impact } \\
\text { Score, } I_{i}\end{array}$ & $\begin{array}{l}\text { Magee et al. } \\
(2010)\end{array}$ \\
\hline $\begin{array}{l}\text { Ranking based on impact to } \\
\text { native species }\end{array}$ & $\begin{array}{l}\text { Component of } \\
\text { "invasiveness", } \\
\text { which also } \\
\text { includes rate of } \\
\text { establishment }\end{array}$ & $\begin{array}{l}\text { Rank between } 0-7 \\
\text { based on number } \\
\text { and severity to } \\
\text { native species }\end{array}$ & $\begin{array}{l}\text { Biodiversity } \\
\text { only }\end{array}$ & No & & $\begin{array}{l}\text { Ricciardi } \\
\text { and Cohen } \\
(2007)\end{array}$ \\
\hline $\begin{array}{l}\text { Decision tree based on } \\
\text { abundance/distribution } \\
\text { and impacts }\end{array}$ & $\begin{array}{l}\text { Aquatic } \\
\text { biopollution }\end{array}$ & $\begin{array}{l}\text { Biopollution level } \\
\text { ranked } 0-4\end{array}$ & Yes & Yes & $\begin{array}{l}\text { Based on subjective } \\
\text { classification of } \\
\text { impacts to native } \\
\text { species, habitats, and } \\
\text { ecosystem function }\end{array}$ & $\begin{array}{l}\text { Olenin et al. } \\
(2007)\end{array}$ \\
\hline $\begin{array}{l}\text { I depends on unique } \\
\text { attributes of the invader, } \\
\text { resident biota, resource } \\
\text { levels, and abiotic } \\
\text { conditions }\end{array}$ & $\begin{array}{l}\text { Organizational } \\
\text { framework }\end{array}$ & NA & Yes & Yes & $\begin{array}{l}\text { Conceptual model } \\
\text { to organize impact- } \\
\text { related research }\end{array}$ & $\begin{array}{l}\text { Thomsen } \\
\text { et al. }(201 \mathrm{I})\end{array}$ \\
\hline
\end{tabular}

$I_{i}=\frac{\sum_{i=1}^{a=9} \text { life history }+\sum_{j=1}^{b=8} \text { eco amplitude }+\left(\sum_{k=1}^{c=7} \text { eco alteration }\right)^{2}}{\text { trait } \max } \times 100$ 


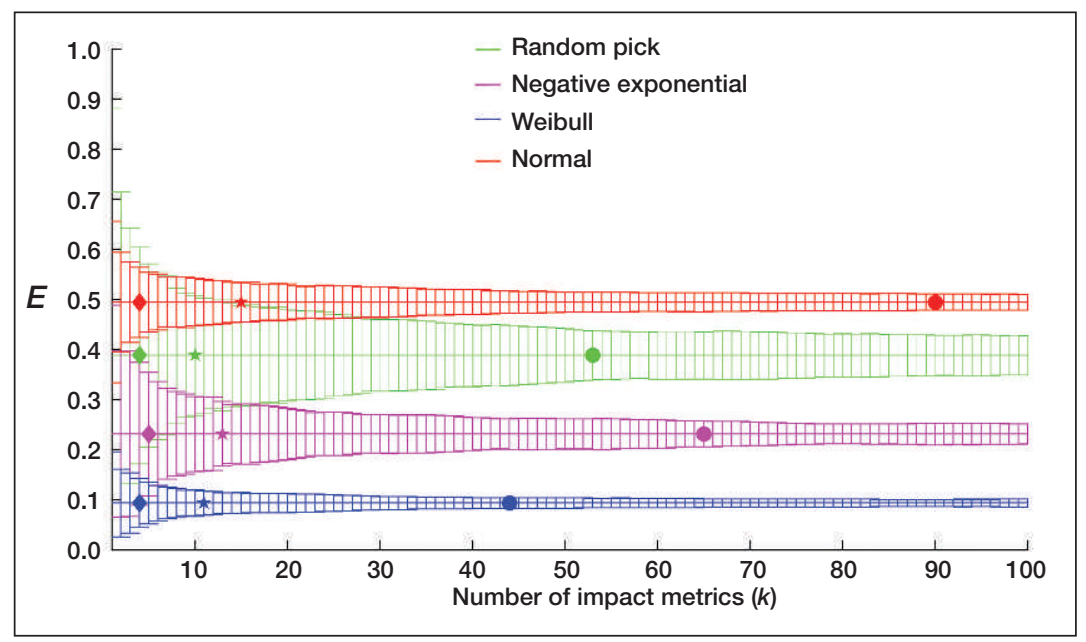

Figure 2. Relationship between $\mathrm{E}$ and the number of $\mathrm{k}$ metrics measured for different $\Delta_{\mathrm{k}}$ probability density functions ( $\left.p d f s\right)$ : random selection of the normal, Weibull (a continuous distribution), and negative exponential pdfs; negative exponential $(\lambda=0.25)$; Weibull $(\lambda=0.1, \mathrm{k}=1.15)$; and normal $\left(\mu=0.5, \sigma^{2}\right.$ $=0.15)$. For each curve, the horizontal line indicates the "total ecological impact", or "real impact". The diamond, star, and circle represent the number of $\mathrm{k}$ metrics capturing 50\%, 75\%, and 90\% reduction in variation from the single metric estimation, respectively. Each distribution was run for 50 iterations. habitat. There are $m$ possible quadrats, the number of which may vary as a function of coverage $(c)$. Therefore, $\Delta_{k}(c)$ is the mean difference of the $k$ th metric caused by the invasive species at a given percent groundcover $(c)$. By taking the absolute value of this relative difference for each metric, we avoid the issue of metrics with opposing signs $(+/-)$ canceling each other out. It would not make ecological sense, for example, if soil moisture was +0.75 and $\mathrm{N}$ pool was -0.75 and they canceled out. Thus, taking the absolute value and using a geometric mean (see Equation 3) avoids several potential issues associated with an integrative metric.

Previously we were limited by the variation in units among impact metrics, but $\Delta_{k}(c)$ now translates all metrics into the common unit of percent difference. The $\Delta_{k}(c)$ function is calculated for each population, which may have variation in the impact metrics in the uninvaded plots simply by where the populations occur spa(hereafter referred to as coverage) is almost universally ignored (see also Table 1).

To account for density dependence, we argue that impact metrics should be recorded as a function of percent groundcover, which largely resolves the issue of comparing species of different sizes. It does not matter how many individuals are present; only their effect at each level of groundcover is of importance. Thus, even if the cover-impact relationship varies within species among ecosystems, our framework can accommodate this where previous frameworks could not. There are several methods of assessing plant coverage, but we suggest using a relative coverage system (cover $\leq 100 \%$ ) that does not utilize categories (eg not the Braun-Blanquet system). Limitations still exist when cover is used as a common metric to compare among species of very different sizes (eg A donax and $M$ vimineum), but coverage remains superior to per capita assessments. The most meaningful comparisons would therefore be among species of relatively similar sizes. Each impact metric would be recorded at a given coverage value that is then compared relative to the mean value of an uninvaded reference site, which is as similar as possible in all biotic and abiotic characteristics (ie ideally only the presence of the invader varies between the sites). Functionally, we would represent this as:

$$
\Delta_{k}(c)=\left[\frac{\sum_{i=1}^{m(c)}\left(\left|\frac{q_{i, k}(c)-\bar{n}_{k}}{\bar{n}_{k}}\right|\right)}{m(c)}\right]
$$

(Equation 2)

where $q_{i, k}(c)$ is the value of the $k$ th impact metric in the $i$ th quadrat $(q)$ in the invaded area at invader coverage $(c)$, and $\bar{n}_{k}$ is the mean of the $k$ th metric in the uninvaded tially. Making "paired" comparisons between the invaded area and the adjacent uninvaded area nicely controls for this. The frequency distribution of $\Delta_{k}(c)$ may vary for each impact metric, as well as by invader coverage. This stresses that $\Delta_{k}(c)$ and $E(c)$ are calculated at each level of coverage in the range available to understand these dynamics, which of course may not always include all values between 0 and 100 (see below for a discussion of this point).

Now that $\Delta_{k}(c)$ has been calculated for each $k$ metric at the relevant coverage levels, they must be combined to create the integrated impact metric $E(c)$ :

$$
E(c)=\left[\Pi_{k=1}^{K}\left(\Delta_{k}(c)+1\right)\right]^{1 / K}-1 \quad(\text { Equation } 3)
$$

where $K$ is the total number of impact metrics recorded. The rooted product is taken to cover the range of $\Delta_{k}(c) \geq 0$. As structured, there exists a theoretical "total ecosystem impact", or "real impact", of the invading population that represents the collective impact if all possible metrics were measured (Figure 2). This hypothetical total ecosystem impact is analogous to the population mean if one could sample every person's height, thus representing the true average height of humans. The total ecosystem impact must obviously be estimated by measuring a sample of the population, thereby serving as an estimate of the true mean (discussed below in relation to the impact cliff). This presents a new standard in invasion ecology, because it suggests that a total ecological impact value exists - not something that can be seen in situ, rather something that can be approximated. Working within this framework liberates us from the orthodox dogma of chasing single (or a few) ecological changes and provides a working model of integration. 


\section{The impact of impact metrics}

The existence of a total ecosystem impact belies the manner in which we currently conduct invasion science. Traditionally, we choose an impact metric of interest, locate a study population, and record a difference (Hulme et al. 2013). This is exemplified in the recent global assessment of invasive plant impacts that demonstrated broad patterns of ecological impacts (Pyšek et al. 2012). The vast majority of these studies do not account for what density, coverage, or population size the impact was recorded. As discussed above, the identity of the metric chosen, its associated $\Delta_{k}(c)$ distribution, and the variance as a function of invader coverage will dramatically influence the conclusions drawn. To demonstrate this, we collected impact data from several studies that met the requirements for the impact function (ie the impact metric must be collected at a range of coverage values) (Maerz et al. 2005; Angeloni et al. 2006). We ran simulations of the invasion cliff function to include the 12 unique impact metrics from these studies (Figure 3). The simulations included a random selection of these metrics over eight iterations, spanning between one and all 12 metrics (Figure 3), which resulted in eight unique surfaces, all of which approach the same value (total ecosystem impact) as more metrics are added (Figure 2). This demonstrates that when a single metric is measured, or even when a few metrics are measured, the results are highly variable. However, as more and more metrics are added, the surface approaches the total ecosystem impact value, just as measuring more people's height approaches the true height population mean. The obvious question then becomes, "how many metrics do I need to measure?"

This integrated framework allows us to estimate the minimum number of impact metrics that would have to be measured to achieve the desired approximation of $E(c)$ (Figure 2). The current limitation to more accurate approximations of $E(c)$ is knowing the distribution of $\Delta_{k}(c)$. Non-parametric methods like bootstrapping or jackknifing could be used to estimate the variance of $E(c)$, but our simulations suggest that a balance between known limitations/assumptions and sampling effort is between 10 and 20 metrics. Measuring five metrics reduced variability of $E(c)$ by $50 \%$, while variation declined by $75 \%$ with 10-20 metrics (although variation continued to decline slowly beyond that; Figure 2).

\section{Will the "real" impact please stand up?}

Once the relationships between each impact metric and level of coverage have been identified, we can calculate $E(c)$, and subsequently the total population impact $I(c)$ :
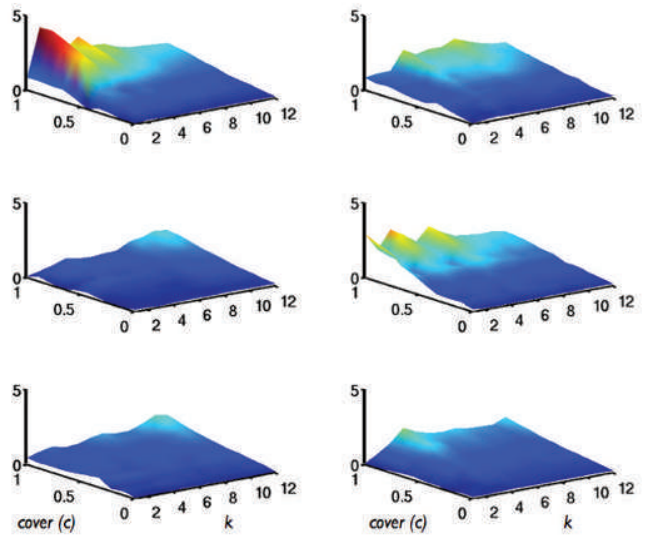

$$
6 \begin{aligned}
& 8 \\
& k
\end{aligned}
$$

ics $(\mathrm{k})$ as a function of

Figure 3. Simulations of impact (E) for 12 impact metrics ( $\mathrm{k}$ ) as a function of
plant coverage (c). The surface on the bottom right is an average of the previous eight simulations. The discrepancies in surface shapes are a result of the order that the $\mathrm{k}$ metrics are added to the impact function. Colors represent a relative value for $\mathrm{E}$, where red and blue indicate higher and lower values, respectively. The impact metrics included plant diversity, aboveground plant biomass, soil organic matter, litter, soil pH, soil water content, bacterial species frog (Rana clamitans) mass (Maerz et al. 2005).

$$
I(c)=E(c) \times R \quad(\text { Equation } 4)
$$

where $E(c)$ is calculated as shown in Equation 3 and $R$ is the population range size (ie spatial extent of the population under study) in square meters (sensu Parker et al. 1999). Thus, $I(c)$ describes the collective impact of each spatially unique invasive population. Functionally, interspecific comparisons could be made at the population level within a target geography using $I(c)$, which has obvious advantages as a management prioritization schema. The three-dimensional representation of $I(c)$ results in the "impact cliff", the shape of which varies based on the integration of $E(c)$ across coverage and range size. The analogy can be drawn between the impact cliff and the population growth curve (Figure 1), where both have a "cliff" or "tipping point" from benign low impact introduction to impactful invader. The impact cliff adds a new dimension to this classic concept.

To demonstrate the utility of the impact cliff surface, we simulated a hypothetical low and high impact species (Figure 4). This simulation shows that the two species have similar impacts at relatively low levels of coverage, but that they diverge greatly in impact as cover increases. The low impact species varies little across all levels of coverage, suggesting it has very little effect on the ecosystems where it occurs. In contrast, the effects of the high impact species increase with coverage, which grows proportionally with the size of the invasion. Thus, if the low impact species is deemed to have an acceptably low ecological impact, then populations of the high impact species in areas with low levels 


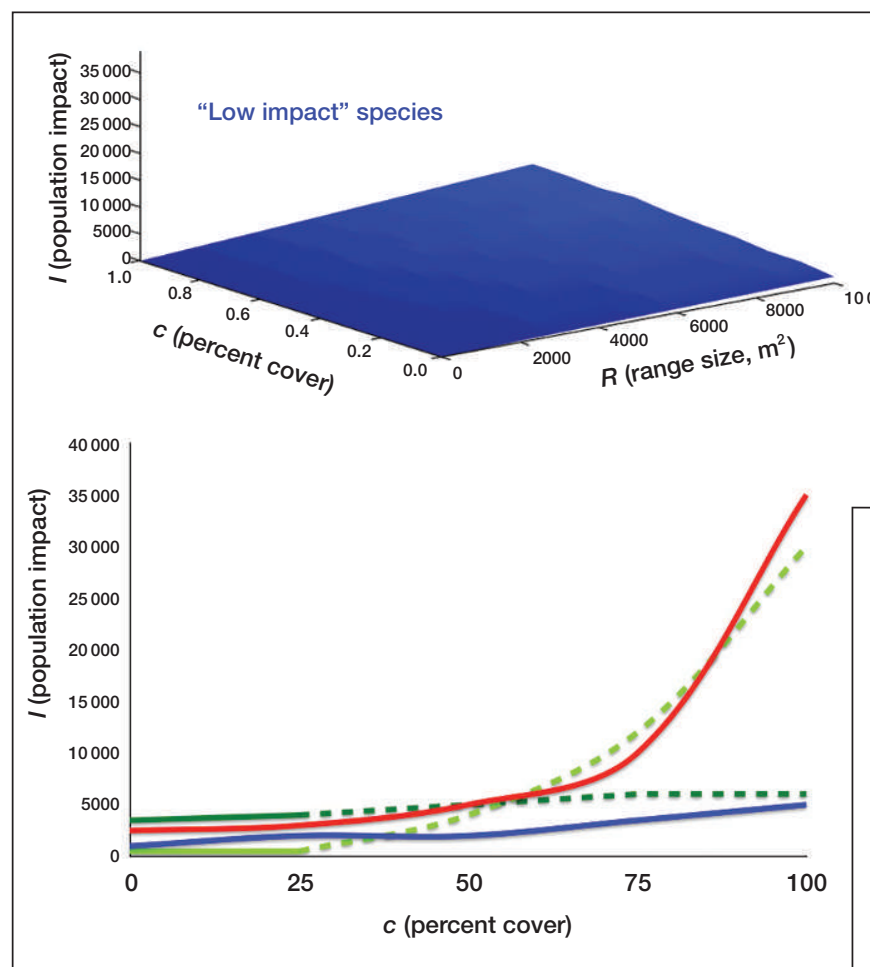

of coverage would be considered low impact, and could therefore occur before the tipping point is reached. However, as coverage and range size increase, this species reaches a critical point after which impacts increase rapidly. This tipping point may serve as the defining stage at which that species "becomes invasive".

In reality, most populations will not represent the full range of coverage levels expressed in the impact cliff (0-100\%). For example, most native species will not occur at very high coverage levels (Figure 4, green lines), which would require creation of experimentally produced high coverage levels. The utility of artificially created high levels of coverage by a particular species and evaluating impact is questionable but may provide insight into how the species would behave if not limited by herbivory, competition, etc. For instance, the understory annual invasive grass $M$ vimineum ranges from $0-100 \%$ coverage in eastern US forests, whereas the ecologically similar native species Leersia virginica rarely exceeds 20\% coverage (DR Tekiela pers comm). An impact comparison between populations of these species could be performed at low coverage levels where both occur (eg solid red and green lines in Figure 4). A more relevant comparison would be conducted at the in situ population coverage and size of each species (red line and dashed green line in Figure 4), which provides a realistic interspecific comparison.

Another interesting comparison could be made between native and introduced populations of the same species. This biogeographical comparison would provide insight into whether the impact has changed following introduction to novel ecosystems. In addition, if specieslevel comparisons are of interest, the population impact (I) values could be calculated across the range of the species: $I_{1}, I_{2}, I_{3}$, and so on. The summation of these val-

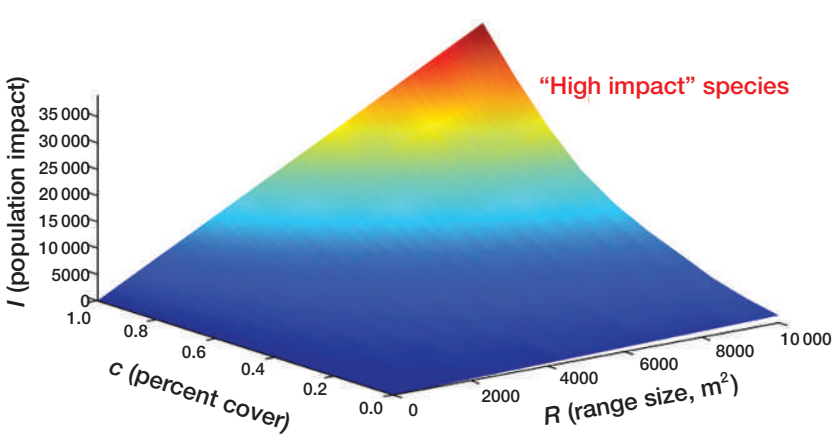

Figure 4. Contrast between a hypothetical high (red line) and low (blue line) impact species, showing the relationship between total population impact (I) and percent coverage (c). The threedimensional graphs depict the impact cliff surface when applied across a range of spatial extent ( $\mathrm{R})$. The green lines illustrate examples where a species may only occur at low levels of coverage, which may result in relatively low (light green solid line) or high (dark green solid line) impact, but anything beyond the existing coverage level would have to be experimentally created (dashed line).

ues would result in a single species impact score. While feasible, the usefulness of this species-level metric is questionable, given that it is populations that are of greatest interest - it is populations of species that are invasive, not the entirety of the species.

\section{Challenges}

There are several limitations to the practical application of the impact cliff framework. One of these limitations is the lack of existing quantitative impact data in general, but, more specifically, impact data as a function of coverage. This precludes conducting impact cliff evaluations using existing data, as we had to cobble together several studies to run our simulations. Here, therefore, we are making a call for studies designed to address ecological impacts as a function of coverage across a range of metrics.

The impact cliff framework does not weight impact metrics based on subjective importance; all impacts are equally important. We anticipate that many will argue with our interpretation that, for example, the effect on native species diversity, soil C pools, litter depth, and soil moisture availability (as examples) are equally important. Just as we have parceled ecosystem functions into specific ecosystem services based on anthropogenic demands, ecologists have ranked several impacts - such as native species diversity and soil nutrient pools - as inherently more important than others (Pyšek et al. 2012). However, there is no empirical reason to weight some metrics as more important than others, and weighting would inherently introduce subjectivity, which we are attempting to remove from the assessment of ecological impacts. Furthermore, different species or populations may have different impacts on various parameters, which can only 
be meaningfully compared when integrated (as we propose) with coverage-based estimators, which are novel and flexible. That said, our framework is flexible enough to accommodate integration of any set of metrics, whether they be subjectively chosen or not. Individual metrics of interest could also be compared through the use of the impact cliff. Because we cannot actually measure all possible impact metrics, we must choose to measure a subset thereof, which have historically been chosen based on researcher bias (Hulme et al. 2013). Yet, by choosing to measure certain metrics and not others we are making subjective decisions regarding their importance to ecosystem function (or the ease with which they can be measured). There may also be issues of colinearity among metrics, which may influence the integrated impact cliff and should be investigated as we move away from limited metric evaluations. Thus, as a scientific discipline, we should identify a common set of independent metrics that would allow a generalizable accounting of invasive plant impacts on the entire ecosystem.

\section{Conclusions}

The impact cliff and associated parameters provide a novel integrative framework to account for all impact metrics of interest; this framework explicitly addresses density dependence and the diversity of metric units. This framework better addresses total ecosystem impacts, allows for intra- and interspecific comparisons, and is a first step toward identifying when species pass the tipping point from benign introduction to impactful invader. Importantly, this could also serve as a useful prioritization tool for invasive plant management.

\section{Acknowledgements}

We thank E Nilsen, T Whitlow, R Dougherty, and L Smith for valuable comments on earlier drafts that greatly improved the manuscript.

\section{References}

Angeloni NL, Jankowski KJ, Tuchman NC, and Kelly JJ. 2006. Effects of an invasive cattail species (Typha $\times$ glauca) on sediment nitrogen and microbial community composition in a freshwater wetland. FEMS Microbiol Lett 263: 86-92.

Byers JE, Reichard S, Randall JM, et al. 2002. Directing research to reduce the impacts of nonindigenous species. Conserv Biol 16: $630-40$.

Davis MA. 2009. Invasion biology. Oxford, UK: Oxford University Press.

Davis MA, Chew M, Hobbs R, et al. 2011. Don't judge species on their origins. Nature 474: 153-54.

DiTomaso JM. 2000. Invasive weeds in rangelands: species, impacts, and management. Weed Sci 48: 255-65.

Ehrenfeld JG. 2010. Ecosystem consequences of biological inva- sions. Annu Rev Ecol Evol S 41: 59-80.

Forseth IN and Innis AF. 2004. Kudzu (Pueraria montana): history, physiology, and ecology combine to make a major ecosystem threat. Crit Rev Plant Sci 23: 401-13.

Hulme PE, Pyšek P, Jaršoì V, et al. 2013. Bias and error in understanding plant invasion impacts. Trends Ecol Evol 28: 212-18.

Lanciotti RS, Roehrig JT, Deubel V, et al. 1999. Origin of the West Nile virus responsible for an outbreak of encephalitis in the northeastern United States. Science 286: 2333-37.

Lockwood JL, Hoopes M, and Marchetti M. 2007. Invasion ecology. Malden, MA: Blackwell.

MA (Millennium Ecosystem Assessment). 2005. Ecosystems and human well-being: synthesis. Washington, DC: Island Press.

Maerz JC, Blossey B, and Nuzzo V. 2005. Green frogs show reduced foraging success in habitats invaded by Japanese knotweed. Biodivers Conserv 14: 2901-11.

Magee T, Ringold P, Bollman M, and Ernst T. 2010. Index of alien impact: a method for evaluating potential ecological impact of alien plant species. Environ Manage 45: 759-78.

NISC (National Invasive Species Council). 2005. Five-year review of Executive Order 13112 on invasive species. Washington, DC: NISC.

Olenin S, Minchin D, and Daunys D. 2007. Assessment of biopollution in aquatic ecosystems. Mar Pollut Bull 55: 379-94.

Parker IM, Simberloff D, Lonsdale WM, et al. 1999. Impact: toward a framework for understanding the ecological effects of invaders. Biol Invasions 1: 3-19.

Pyšek P and Hulme PE. 2009. Invasion biology is a discipline that's too young to die. Nature 460: 324.

Pyšek P, Jarošík V, Hulme PE, et al. 2012. A global assessment of invasive plant impacts on resident species, communities and ecosystems: the interaction of impact measures, invading species' traits and environment. Global Change Biol 18: $1725-37$.

Ricciardi A. 2003. Predicting the impacts of an introduced species from its invasion history: an empirical approach applied to zebra mussel invasion. Freshwater Biol 48: 972-81.

Ricciardi A and Cohen J. 2007. The invasiveness of an introduced species does not predict its impact. Biol Invasions 9: 309-15.

Richardson DM, Pyšek P, Rejmanek M, et al. 2000. Naturalization and invasion of alien plants: concepts and definitions. Divers Distrib 6: 93-107.

Rosenzweig M. 2001. The four questions: what does the introduction of exotic species do to diversity? Evol Ecol Res 3: 361-67.

Sala OE, Chapin III FS, Armesto JJ, et al. 2000. Global biodiversity scenarios for the year 2100. Science 287: 1770-74.

Schmitz DC, Simberloff D, Hofstetter RH, et al. 1997. The ecological impact of nonindigenous plants. In: Simberloff D, Schmitz DC, and Brown TC (Eds). Strangers in paradise: impact and management of nonindigenous species in Florida. Washington, DC: Island Press.

Simberloff D, Souza L, Nuñez MA, et al. 2012. The natives are restless, but not often and mostly when disturbed. Ecology 93: 598-607.

Thiele J, Kollmann J, Markussen B, and Otte A. 2010. Impact assessment revisited: improving the theoretical basis for management of invasive alien species. Biol Invasions 12: 2025-35.

Thomsen M, Olden J, Wernberg T, et al. 2011. A broad framework to organize and compare ecological invasion impact. Environ Res 111: 899-908.

Vilà M, Espinar JL, Hejda M, et al. 2011. Ecological impacts of invasive alien plants: a meta-analysis of their effects on species, communities and ecosystems. Ecol Lett 14: 702-08. 